\title{
DOIS MENINOS: A CONSTRUÇÃO DO AMOR PERDIDO EM DOIS ROMANCES CONTEMPORÂNEOS
}

\author{
Leandro Soares da Silva*
}

RESUMO: Este artigo analisa dois romances contemporâneos: Vista do Rio, de Rodrigo Lacerda, e O amor dos homens avulsos, de Victor Heringer. A análise em questão procura distinguir a composição de romances que tratam de temas muitos semelhantes: a autobiografia, a memória e o relacionamento afetivo com outro homem, sexual ou não. As diferenças de composição levam a resultados distintos no que concerne tanto à autobiografia quanto à memória, mas acabam por se encontrar no que se refere à identidade sexual. Assim, ambos os livros oferecem uma leitura na qual a questão da identidade seria menos importante na definição dos laços afetivos entre homens.

PALAVRAS-CHAVE: Literatura brasileira; afetividade; narrativa pessoal.

\section{Introdução}

A existência dentro do cânone literário de um conteúdo que atualmente chamamos de LGBT não parece mais ser uma ideia que cause estranhamento. Aqui ou no exterior, muita pesquisa tem sido realizada para demonstrar a presença de temas, personagens e situações que a sensibilidade moderna consegue identificar como bastante própria de pessoas cuja sexualidade não é hegemônica. Esse trabalho a partir do cânone geralmente opta por dois caminhos: trazer à tona essas experiências "dissidentes", por meio da análise e estudo teórico da representação; ou reler o cânone sob outra perspectiva. Nos dois casos, os resultados desfazem a rasura de leituras anteriores sobre esse aspecto do cânone - não

\footnotetext{
* Professor da Universidade do Estado da Bahia (Ufba). Doutor em Estudos Literários pela Universidade Federal de Minas Gerais (UFMG).
} 
é que não exista uma literatura de temática LGBT; o que não havia era vontade (ou oportunidade) de ler o que sempre esteve aí. Muitos estudiosos já apontaram isso (p. ex. BARCELLOS, 2006 ou COSTA, 2010), com sugestões e análises sobre como os textos canônicos tendem a ser lidos pelo viés da heterossexualidade compulsória. Se os estudos sobre sexualidades atingem o cânone e fazem-no dizer o que por muito tempo foi silenciado, muito mais conseguem com textos não canônicos.

Podemos inferir que, no mínimo, desde as lutas por direitos civis e as políticas identitárias do século XX, homens e mulheres escritoras têm se engajado em produzir obras mais contundentes no trato da sexualidade ou dos problemas de gênero. Leitores e leitoras acadêmicas, por seu turno, trataram de apreciar criticamente essa produção e erguer postulados teóricos. O orgulho de possuir uma identidade proscrita, como resultado das políticas de identidade, fortaleceu a parcela do público que tinha interesse em ler ficções mais próximas de suas experiências pessoais.

Essa representatividade não trouxe para o campo literário apenas o debate político sobre as identidades LGBT, tampouco resultou num mero consórcio entre mercado e consumidor, mas propiciou a invasão de novas abordagens dos temas, formas de escrita e sensibilidades. Similar ao que aponta Raymond Williams (1991, p. 1-7) a respeito de como a popularização dos métodos de imprensa e letramento levaram à produção de novas formas de escrita literária, podemos considerar que a positivação das identidades subalternas, por exemplo, propiciou o surgimento de obras compostas por sujeitos mais conscientes da necessidade política de representatividade. Para os estudos literários isso também tem significado o questionamento da formação do cânone e dos pressupostos da crítica, além da introdução de novas teorias e abordagens no seu repertório. Esse território é contestado pela teoria literária tradicional (p. ex., PERRONE-MOISÉS, 1998), sem considerar que sempre houve política e ideologia mesmo no mais neutro clamor pela qualidade literária imanente. Estamos falando de uma história amplamente conhecida, apesar de ainda provocar debates mais ou menos calorosos. 
Este artigo pretende analisar textos surgidos depois do cenário acima resumido, para tentar entender a quais caminhos nos trouxe a política identitária. Particularmente, dois romances publicados neste século: Vista do Rio, escrito por Rodrigo Lacerda e lançado em 2004, nove anos após sua estreia como romancista; e O amor dos homens avulsos (2016), terceiro livro de Victor Heringer, que estreou em 2011 com Automatógrafo. Os dois romances têm narradores que escrevem suas autobiografias tendo como foco o relacionamento com outro homem. Discutiremos como os livros se assemelham na construção desse tema e como se separam nas escolhas formais e textuais. Essas diferenças não são apenas efeitos do estilo - na verdade, a intenção é discutir como o estilo e a composição têm a ver com o problema da identidade.

\section{Narrativa pessoal e literatura}

Marco Aurélio, narrador de Vista do Rio, rememora sua vida a partir do relacionamento com Virgílio, seu primo adotado. O cenário, mas também de certa forma personagem da trama, é o edifício Estrela de Ipanema. Enquanto Marco é contido e até acomodado, Virgílio é impulsivo; se Marco é heterossexual, Virgílio prefere não se definir nesses termos: explora sua sexualidade de forma livre e escolhe nomear-se bissexual. Muito próximos durante a infância e adolescência, suas vidas tomam rumos opostos quando crescem e deixam de morar no mesmo prédio. Reencontram-se quando Virgílio, já adulto, agoniza no hospital em decorrência do HIV.

O amor dos homens avulsos é narrado por Camilo e conta sua história de amor com Cosme, ou Cosmim, num subúrbio carioca. Cosme chega à casa por intermédio do pai, um médico que possivelmente trabalhava para a ditadura, por quem é adotado. Camilo era solitário até sua chegada; com um problema na perna que o impedia de andar, é retraído e confuso acerca da sexualidade. Os dois irmãos logo se apaixonam e vivem intensa e livremente a relação, até o dia que Cosme é assassinado.

Os dois romances são memórias da juventude que impactam o presente da narração. O amor ou a amizade construídos nesse período são constituintes da história de vida 
de quem fala, seja Marco ou Camilo; daí se depreende a importância da relação masculina para suas narrativas. Em ambos os livros a cidade é o Rio de Janeiro, como metonímia do edifício ou do subúrbio. A cidade vai ser tanto o espaço da história quanto simbolizará seu desdobramento, espelhando a vida de cada narrador. Mas enquanto o amor homossexual nutre a trama de Homens avulsos, é a amizade que torna as vidas de Marco e Virgílio inseparáveis.

A escolha por narrativas de teor biográfico não deve ser apenas uma coincidência que partiria da decisão de seus autores empíricos. Entendida aqui como narrativa pessoal, a autobiografia fictícia desses personagens produz um atestado de autenticidade que permite à trama a visualização da memória como um sítio arqueológico, para citar Walter Benjamin. O trabalho da memória não é apenas desenterrar as ruínas e trazê-las para o presente; o próprio lugar de escavação também faz parte do cenário.

A língua tem indicado inequivocamente que a memória não é um instrumento para a exploração do passado; é, antes, o meio. É o meio onde se deu a vivência, assim como o solo é o meio no qual as antigas cidades estão soterradas. Quem pretende se aproximar do próprio passado soterrado deve agir como um homem que escava. (BENJAMIN, 1987, p. 239.).

Quem se vale da memória para a narrativa pessoal enfatiza sua autoridade para realização do trabalho. Se eu conto a minha história é porque se compreende que eu seria a pessoa mais apta para fazê-lo. Narradores ficcionais de autobiografias mimetizam a narrativa pessoal tomando dela a necessidade de reconhecimento pelo outro (leitor ou interlocutor), mas, ao fazer isso, eles conseguem expor o próprio regime de narração pessoal. Quem fala de si pretende oferecer continuidade e coerência para experiências que frequentemente não possuem nenhum desses atributos, mas a narrativa pessoal não literária lida com normas cuja temporalidade não coincide com o tempo da vida (BUTLER, 2015, p. 50). Quando conto minha história, ou sou obrigado a fazê-lo, lido com uma restrição nem sempre percebida: só posso narrar a mim mesmo de acordo com uma matriz discursiva 
que eu não tenho como mudar e que já existia antes do meu aparecimento no mundo.

Ao tomar como foco a autobiografia, a ficção tem condições de expor exatamente essa restrição na raiz da narrativa. A literatura não precisa do referente, nem da continuidade, para oferecer uma narração coesa. Por outro lado, também a escrita literária deve se submeter à tradição, ao conjunto de textos cujo arcabouço discursivo nos permite diferenciar a literatura de outros textos. Não se escapa da tradição porque ela ainda permanece como parâmetro. Na mesma medida, se pretendo ser reconhecido como sujeito devo seguir as normas de inteligibilidade social para narrar a mim mesmo.

Em Vista do Rio e $\mathrm{O}$ amor dos homens avulsos isso é tratado com diferenças que são bastante coerentes com os personagens narradores. Marco é um historiador de formação clássica e sua linguagem quer alcançar a clareza por meio de uma linguagem estudadamente fluida; Camilo, por outro lado, é errático e fragmentário, um homem sem medo de ser medíocre. A narrativa pessoal de Marco tem um projeto de calculada espontaneidade que joga com as fórmulas convencionais de escrita para construir um retrato da amizade e da existência como ruína; a de Camilo é fala nostálgica, o trivial aparecendo com a mesma frequência com que é deslocado.

A narrativa pessoal produz a impressão, para seu emissor, de que ele possui agência sobre a própria identidade. Se me perguntam quem sou eu, respondo para tentar alcançar o outro - quero ser identificado, quero demonstrar meu lugar de fala, quero ter esse lugar reconhecido. Em Vista do Rio, o contraste se estabelece entre os primos menos como produto de identidades sexuais diferentes (hétero/bissexual) e mais como maneira de acesso à experiência. Marco é o narrador cuja bagagem é pobre; ele gostaria de aprender como Virgílio, que vivencia e se dispõe a experimentar com maior radicalidade. Sua narrativa, portanto, revela cuidado e escolha na estruturação. Em Homens avulsos, a identidade pessoal está em segundo plano porque interessa a Camilo contar do seu amor e da ausência. Não é só um homem gay olhando para trás: é um homem ainda apaixonado. A homossexualidade importa menos e é quase não nomeada no seu discurso, porque ela parece acidental. 
Mesmo que Cosme tenha sido morto por ser gay (o que o narrador não diz), não é a homofobia que funda sua experiência: é o amor.

O tipo de narrativa pessoal desses livros é semelhante no sentido de que para eles não existe a possibilidade de responder ao "Quem és?” com uma história das origens. Embora, em última análise, toda narração funde a origem de seu narrador, o efeito desses dois romances causa maior interesse por seus métodos de construção do que pela representação de sexualidades não normativas. Virgílio não é o amigo bi fornecedor de casos para nosso divertimento ou escândalo - seu paradigma é o do sujeito que opta pela experiência. Cosme e Camilo não são adolescentes gays definidos pelo amor proibido de inevitável fim trágico, a história deles é a do amor ordinário que foi interrompido. A narrativa os descreve fazendo o que rapazes de sua idade costumam fazer: jogando bola, descobrindo o sexo, brincando nos quintais com os vizinhos - a homossexualidade não é escondida nem reprimida pelos outros. É como se o narrador até se esforçasse para torná-la irrelevante.

\section{Linguagens da memória e da ausência}

Exploraremos as diferenças de forma presentes na expressão de cada narrador, mas sem querer denotar alguma cisão substantiva entre os romances; há semelhanças. Lacerda explora o artificialismo da simplicidade, cada frase e parágrafo disfarçando cuidado na linguagem. Há uma beleza nisso similar ao retrato amargo da cidade, mas sobretudo correspondente ao declínio do esplendor modernista do prédio. Este literalmente se mostra no livro, em figuras geométricas e sombras delineadas num intricado e desnudo desenho que antecede o primeiro capítulo, assim como o estilo narrativo é incapaz de ocultar sua construção como cuidadosamente desenhada para soar simples:

Quase esgotado, o beija-flor foi se entregando, largando, descendo. Desistir começou a ser uma opção. Bastou o rabo encostar nas hélices, contudo, que suas energias voltaram. Com sorte roto, com azar já ferido, o bicho sumiu de novo. Suas asas ocuparam um espaço maior que elas, num frenesi que só o medo da morte é capaz de promover. (LACERDA, 2004, p. 12) 
O livro de Heringer tem a seu lado o humor que nem sempre é irônico, muitas vezes autodepreciativo, para disfarçar a pieguice e a ternura. Há material suficiente para adoçar os sentimentos do leitor, mas a linguagem se ergue cambaleando, embevecida do coloquialismo da fala suburbana. Não há, contudo, artificialismo para conduzir esse jogo. O texto flui como fala de um homem comum que calça botas em tempos de chuva para ir à padaria. Este recurso também espelha a natureza da história, pois essa narração não oculta sua origem profunda, mas medíocre. O narrador não precisa perseguir com esmero a simplicidade das palavras porque narra para exaltar a mediocridade de sua condição. Faz parte do jogo ofertado pelo romance, coagulado de fotos, carimbos, vinhetas e desenhos - uma coletânea do ordinário que preenche a história de toda vida. "No começo, nosso planeta era quente, amarelento e tinha cheiro de cerveja podre", início do livro, conduz a "Os subúrbios do Rio de Janeiro foram a primeira coisa a aparecer no mundo, antes mesmo dos vulcões e cachalotes", no parágrafo seguinte (HERINGER, 2016, p. 11). A transição da lama primordial ao subúrbio carioca é mediada pelo cheiro de cerveja, um acréscimo ligeiramente irônico e familiar que é muito próprio do estilo do narrador.

A nostalgia de ambos os livros se expressa com diferenças orientadas pela falta. Em Lacerda, a busca pela expressão horaciana de simplicidade bela nasce da reflexão complicada igual a necessária para erguer uma obra arquitetônica. Canta o louvor da perda da inocência desde a infância, por isso tenta reconstruir a linguagem dessa falta. $\mathrm{O}$ estilo é simples, mas não natural. Em Heringer, há uma inocência que nunca se perdeu; embora castigada pela ausência, ela vive reclusa na bolha quente de quem nunca saiu do subúrbio, dos seus costumes, da sua domesticidade. Aqui se reconstitui a juventude com a linguagem da juventude, manchada pela perda, mas ainda próxima (inclusive materialmente, por meio das fotos, rabiscos e pequenos souvenires que não desatam o narrador de seu passado e aparecem como figuras ao longo do livro). Essa proximidade se acentua na recriação do primeiro amor, agora redirecionado para o amor paternal - o romance termina com Camilo adotando uma criança. 
Vista do Rio não possui o mesmo conforto - sua história é instantâneo sem futuro, fora o das ruínas. Como o prédio modernista, o Rio se deteriora, as relações são fadadas ao estranhamento e o passado só sobrevive como memória, e mesmo esta é corrompida. Já o subúrbio do livro de Heringer é a parte mais antiga e mais duradoura do Rio de Janeiro, conserva sua história de familiar violência, autoengano e amizades de superficialidade densa que fazem a existência menos trágica. É possível se deleitar na memória e banhar-se na nostalgia como se choram as dores no balcão do botequim. Assim o passado se refaz no presente, caseiro e íntimo como um animal doméstico.

Os projetos de escrita são guiados pela memória e correspondem a motivações e eventos anteriores. Em Vista do Rio, a linguagem anseia por ser construída com deliberada simplicidade para exibir força e resistência frente ao tempo pouco reverente, que vê coisas e pessoas se substituírem até restar apenas a lembrança. O liame de amizade entre Marco e Virgílio, conquanto linha de traço que risca o trajeto do romance, é sobretudo matéria de meditação para uma vida que já é ruína antes de ser construção.

O narrador do livro de Heringer quer guardar o passado do amor idílico, ainda que proibido, e fala com a ironia agridoce de quem testemunha a casa suburbana com piscina se transformar em quitinetes. Daí que a língua dessa memória é imbuída de mocidade, dos símiles e imagens angariadas da rua e dos sentimentos sem nome do homem comum. Durante quatro páginas, uma sucessão de quadrilhas drummonianas - "Como Denilson amou Raiane, como Aline amou Michael, como Raquel amou Guilherme, que morreu de meningite" (HERINGER, 2016, p. 69) - invade o livro para compará-las com o amor do narrador por Cosme. Uma nota do autor nos informa a origem dessa lista quase interminável: os futuros leitores enviaram pela internet suas histórias do primeiro amor com a finalidade de "escrever um parágrafo do livro" (HERINGER, 2016, p. 153). A contribuição é fatalmente anônima, cada nome e repetição nem menos nem mais singular do que qualquer ficção, adicionando outra camada de verniz barato à experiência de amar.

A maneira como cada narrativa lida com a linguagem também reflete esse construirse na e por meio da memória. Quando, em Vista do Rio, após ler um poema do narrador, 
composto de frases das mais pedestres (“Comecei a jogar tênis,/ perdi dois relógios”), Virgílio sentencia sobre essa simplicidade: "Até parece que você não planeja cada mínimo passo que dá". Marco Aurélio se defende com "Esse poema não é afetado" (LACERDA, 2004, p. 154-155). O romance expõe nesse passo o grande projeto por trás da narrativa de Marco: erguer-se como arquitetura que exibe "um concreto cheio de si", mas em "perfeita sintonia", reafirmando "a superioridade indiscutível do intelecto e da razão" (LACERDA, 2004, p. 44). Esse artifício nasce do distanciamento ou vem com a herança, como ser professor de História Antiga é um hábito adquirido de seu pai, professor da matéria. A graça da razão clássica, de recatada beleza, é o parâmetro discursivo do narrador.

A elaborada abertura, por exemplo, constrói o grotesco de um colibri preso no copo de liquidificador até ser reduzido a uma massa metálica. Esse episódio de sadismo infantil marca no livro menos um caráter que permanece na vida adulta, como era de se esperar, do que um exercício de estilo para descrever as maldades cúmplices da infância. A exibição do intelecto é predileção de Marco em várias passagens, dos seus conhecimentos de arquitetura à literatura antiga, da etimologia germânica a semiótica das cores. Essas pequenas digressões educativas pretendem ocultar a incapacidade do narrador em apreender a experiência. Como a prosa meticulosa, sua vida não é espontânea, se faz a partir de saberes que ele leu nos livros - eis o contraste essencial que faz com Virgílio. Este se entrega aos acontecimentos e pessoas com uma fúria que castigará seu corpo, mas que o levará a ganhar altura, como no capítulo final, quando se entrega ao voo de asa-delta enquanto Marco se prende ao chão temendo "morrer sem viver", "morrer antes de amar sem razão. Antes de amar acima de tudo" (LACERDA, 2004, p. 197).

Em $O$ amor dos homens avulsos, narrar oferece um consolo diverso do desejo de construir com autonomia sua própria história. Narrar é uma maneira de esquecer pelo avesso, para se convencer "de que tinha inventado isso tudo, inventado Cosmim, um assassino marido da babá, meu pai anjo de tortura” (HERINGER, 2016, p. 52). Como a lembrança de uns versos lhe ensina, nem os poetas devem “dizer coisas assim na vida comum."; e 
conclui: "Cosmim morreu na vida comum". Fora da vida comum a tragédia pode ser ressignificada, o passado reescrito e a ambiguidade resolvida. Camilo tem muitas razões para desejar isso. Sem ambições maiores, a mediocridade não lhe pesa. Ele está preso ao subúrbio como preso a sua deficiência física. Não sabe se Cosme é o filho sequestrado de alguma torturada ou se essa história é rancor da mãe; como ele afirma, "Carimbo e história são fáceis de inventar" (HERINGER, 2016, p. 37).

Ele narra sua biografia numa linguagem que absorve o cotidiano, das revistas de celebridades aos ídolos de futebol, do Super-Homem de Hollywood a língua de boi no almoço. Tenta capturar do ambiente o fervor inaudito das coisas provisórias que definem nosso tempo (num carimbo lê-se: “A Revolução de 64 é irreversível e consolidará a Democracia no Brasil"). O sinal de definitiva autoridade com que certas coisas do passado permanecem - fotografias, cadernos, documentos - pode ruir ao gosto da história, essa com h minúsculo que Camilo tece e com a qual se entretém. Quando se encanta por Renato, neto do assassino de Cosme, revive no garoto a paixão juvenil mas a reconduz para um amor paternal, pelo cuidado, mas também para aliviar a solidão. Reescreve com ele sua própria história, não para afastar a perda de seu primeiro amor, mas para que ele vingue além da morte.

É afinal o amor, seja nesse livro ou no de Rodrigo Lacerda, que se apresenta como cerne da narrativa. Virgílio e Cosme representam, em ambos os livros, o conflito, o imprevisível e a reviravolta que dão cor à vida dos narradores. A maior diferença consiste na composição de cada romance, ou no projeto subentendido. Cada um articula seus temas de maneira que o produto final corresponde no plano de execução aos temas abordados.

\section{O livro}

Numa divisão didática estabelecida por Roland Barthes, há o Livro e o Álbum. Enquanto o primeiro é "uma representação do universo", "homólogo ao mundo", o Álbum é seu contrário, "universo não-uno, não hierarquizado", "puro tecido de contingências" (BARTHES, 2005, p. 130). Barthes estabelece essa distinção no âmbito da preparação do 
romance, mas consente que as obras finais podem corresponder tanto ao Livro quanto ao Álbum. Para ler os romances de Lacerda e Heringer segundo essa fórmula, precisamos interpretá-los como projetos de escrita de seus narradores: a ruína de Marco e a morte da "vida comum" no texto de $O$ amor dos homens avulsos.

As pretensões de Marco em construir uma sofisticada simplicidade de escrita remetem-nos à barthesiana ideia de Livro como "filosofia monista (estrutura, hierarquia, ratio, ciência, fé, história)" (BARTHES, 2005, p. 131). Vista do Rio é o resultado do trabalho de seu narrador para ordenar o passado e justificar o presente. Ele consegue, de fato, realizar isso. Sua história corre paralela a de Virgílio, assim como às histórias do prédio e da cidade onde cresceu. As descrições do Estrela de Ipanema servem de metáfora não só do projeto social, mas, por extensão, também da própria construção do romance:

O Estrela de Ipanema pressupunha uma dinâmica evolutiva, sim, porém vitaminando-a com uma farta dose de instantaneidade. [...] Era, em si, um triunfo do otimismo, da técnica, da nova sociedade. Aquele edifício era a matéria dos novos sonhos. Nele a humanidade adquiria a mesma força criativa da natureza, fazia seu tempo, afirmava sua razão, libertava a si própria em todos os níveis. (LACERDA, 2005, p. 53-54).

Quando Marco escreve, o Estrela não mais existe. Logo, seu esplendor arquitetônico é um projeto sem sucesso, abortado ou incongruente, e nesse sentido também representa a própria trajetória do narrador. Ele deseja guardar, via escrita, a ruína do prédio e da vida. “O futuro do Livro é o Álbum”, diz Barthes (2005, p. 133), “assim como a ruína é o futuro do monumento":

A ruína, de fato, não está do lado da Morte: ela está viva como Ruína, consumida como tal, esteticamente constituída, germinativa. Passamos nosso tempo (pela atividade de nossa memória, ver Valéry) criando ruínas, e alimentando-se delas; alimentando nossa imaginação, nosso pensamento. (BARTHES, 2005, p. 134). 
Criar ruínas é um bom nome para a atividade de Marco como narrador. Seu Livro constrói memórias de pessoas e coisas e nutre-se delas. Se é que lhe coube qualquer momento de glória, sua vida seria menos gloriosa do que o Rio, o edifício e Virgílio um dia foram. Historiador do resíduo, alimenta-se de restos; a memória não lhe serve para olhar para trás, mas para continuar seguindo em frente. Daí que o romance tem inícios para situar o desenvolvimento do Livro: a personalidade ousada de Virgílio, seu estatuto de rebelde, a sexualidade - tudo isso inicia a narrativa. Marco conta a história para unificar a vida e isso o diferencia de Camilo, compositor do Álbum.

\section{O álbum}

Em Homens avulsos, o início é uma paródia das descrições cosmogônicas cujo incipit é um informe meteorológico; ao longo do livro, vários tipos de textos sofrerão o mesmo destino: a anotação, a lista, o diálogo e assim por diante. O projeto de Álbum decorre dessa natureza heterogênea da narrativa (que também inclui fotos, desenhos de criança, cópias de boletins escolares etc.) como desejo de escrever para superar a vida. Desejo que surge do contato com a literatura:

Li uma vez num poema que nós "somos bonecos de lava endurecida/ e é com lágrima que nos amoldam”. [...] Nunca ninguém me disse nada parecido, nem o poeta desse mesmo poema deve dizer coisas assim na vida comum. Então é a vida comum que tem que morrer; Cosmim morreu na vida comum. (HERINGER, 2016, p. 53)

Que complicação esse trecho introduz para nossa leitura do romance? Ele vem para explicar o desgosto de Camilo ao sobreviver com uma memória que lhe é custosa. Assim, o desejo de "matar a vida comum" é associado à vontade de o vivido ser inventado. Mas por que isso nos complica? Ao ler o livro, desde o título, percebemos de imediato seu amor ao comezinho, doméstico e, em uma palavra, medíocre. Ou comum, como na locução na qual esta palavra é adjetivo: "vida comum" remete tanto ao tempo cotidiano com seus 
afazeres e afetos pouco notáveis, quanto à existência com suas misérias e glórias ordinárias. É pelo menos esses dois sentidos que precisam ser mortos.

Então a escrita do romance, na voz de Camilo, é o ato inaugural de recusar essa dimensão dupla de “vida comum”. Se essa sugestão lhe chega de um poema, não é mero acaso. Flaubert: "A vida só é tolerável na condição de não se estar nela1". Cioran: "A vida só é tolerável pelo grau de mistificação que se põe nela” (1989, p. 111). Cecília Meireles: “A vida só é possível reinventada” (1987, p. 195). Essas citações resumem certa mitologia da escrita literária, o adiamento da vida em favor de sua simulação, entendida aqui como ensaio a partir do qual a experiência pode ser testada.

A narrativa é a simulação que põe à prova os restos com os quais se vive, vestígios vigentes do passado que conduzem mais à reescrita da história pessoal do que a sua origem. Se pudéssemos descrever este narrador com um projeto literário, certamente diríamos que ele não procede à escrita do Livro, ou seja, da narrativa totalizante - mas, antes, para a sua preparação ou Álbum. Camilo é o narrador-bricoleur do próprio passado, colecionando no ir e vir entre outrora e agora o ápice de uma vida melancólica - o breve namoro com Cosme.

A História emerge da superfície menos como contexto e mais como cenário: naquela época da ditadura, no subúrbio carioca, dois adolescentes se amaram e foram privados pela tragédia. A narrativa subentende, e assim se abre às interpretações, o significado do momento histórico como pano de fundo do amor, mas não é para entender o passado nacional que Camilo escreve. Ele escreve para superar a vida. Simulação: "Viver? nossos criados farão isso por nós ${ }^{2}$ ".

Mas existe outro narrador no livro, aquele que lhe põe o título. Camilo se cala após a adoção clandestina e muito à brasileira de Renato, que muito lhe lembra Cosme (por sua

\footnotetext{
1 “La vie n'est tolérable qu'à la condition de n'y jamais être." Carta a Louise Colet, 6 de março de 1853. Disponível em: <http://flaubert.univ-rouen.fr/correspondance/conard/lettres/lettres1.html>

2 Villier de L'Isle-Adam, Axël. Disponível em: https://fr.wikisource.org/wiki/Page:Villiers_de_L’Isle-Adam__Axël,_1890.djvu/295
} 
vez adotado pelo pai de Camilo). Depois disso o livro apresenta uma divisão: "Um sol dentro de casa". Entra em ação um narrador heterodiegético que inventaria o futuro do protagonista, aquilo que acontece depois da entrada de Renato em sua vida. Embora o tom não seja diferente do narrador anterior, esse deslocamento de enunciação quebra o ritmo autobiográfico do texto:

A ex-mãe vai querer o garoto de volta. Se o telefone tocar no dia de Natal e ela avisar que um oficial de Justiça, que o primo policial, que ela mesma vai buscar. Renatinho vai se dar. Ainda é criança, tudo é definitivo e impotente. Vai chorar, talvez chore, tomara que chore. Mas ninguém bate à porta. $\mathrm{O}$ telefone.

O telefone vai tocar. Mas, se tocar, pode ser qualquer um. (HERINGER, 2016, p. 152)

Pode-se dizer que os últimos parágrafos do livro (acima) deixam a ação no suspense para permitir a abertura do porvir, mas eles se destacam mais pela enumeração do previsível - tanto no ritmo das sentenças quanto no que elas expressam. "Um sol dentro de casa" é um desfecho cuja função é completar o Álbum composto por Camilo, ou, por assim dizer, torná-lo Livro. Ao fecharmos o volume, relemos em sua capa "O amor dos homens avulsos" como uma extensão desse epílogo, um título que não anuncia mistério algum, mas descreve exatamente seu conteúdo. Porque não existe tamanha ingenuidade, somos obrigados a considerar a metonímia - avulso: isolado, arrancado à força, separado.

\section{Dois meninos}

Virgílio e Cosme vigem como memória de Marco e Camilo, ao ponto de não lhes ser possível narrar sem evocá-los. Essas quatro figuras podem ser lidas, com efeito, como duas. Marco-Camilo é antípoda de Virgílio-Cosme: de um lado o isolamento, a pusilanimidade, aurea mediocritas; do outro lado a ruptura, a espontaneidade, sapere aude (Horácio). Virgílio-Cosme entra na história para oferecer aventura e promessa, seja de uma vida em comum ou de escapar da existência pedestre; mas tais promessas não vigoram. 
Virgílio é testemunha, no começo do romance, de uma cena capital: flagra o empregado da família, Jairo, fazendo sexo com o próprio filho e inicialmente só o revela a Marco. Sua cumplicidade resulta no triângulo sexual indireto que formará com Miguel, que não se opõe e até se satisfaz na relação incestuosa com Jairo. Virgílio escolhe o risco ao conforto, expõe sua bissexualidade desde adolescente e a vive sem frustrações. Afasta-se de Marco à medida que cresce, cada um seguindo ou a via do excesso ou a da classe média. O reencontro como adultos ocorre quando Virgílio já está no leito do hospital.

Cosme chega na família como irmão adotado, mas passa a amante de Camilo. O amor dos dois não é lascivo, nem clandestino: os amigos da vizinhança sabem e convivem bem com o namoro e não há capitulação da parte do narrador, um menino tímido e com defeito físico, em assumir o romance. O amor é vivido como idílio e realização. Ao lado de Cosme, ele parece encontrar a alegria que a reclusão lhe vetava. Quando Cosme é estuprado e morto, Camilo volta ao estado anterior de isolamento.

A sexualidade é nos livros força de transformação. Ao contrário de Virgílio, Marco não parece ter se permitido a experimentá-la com a mesma liberdade - a cena que descreve seu encontro com a prostituta é patética e triste. Camilo insinua que apenas provou tal liberação enquanto Cosme estava vivo. É como se depois ou antes dele não houvesse frêmito de amor. Os livros trazem, porém, versões diferentes de sexualidade, com consequências distintas. Em Vista do Rio, é difícil não apontar que o vírus é a paga do excesso; em Homens avulsos, por outro lado, a morte é resultado mais da brutalidade e da violência do que da homofobia. A violência rasga o texto desse romance em vários momentos, de alusões à ditadura às notícias de jornal, dos ruídos de programas sensacionalistas ao cotidiano miserável da cidade.

Mas existe uma semelhança que é a ausência de culpa. Ao contrário de muitas histórias de formação, o desejo sexual proibido (homo ou bissexual) não chega junto com a angústia de possuir uma identidade proscrita. Mesmo a experiência do HIV nunca é explicitamente descrita como consequência do desregramento, já que a atitude do Virgílio enfermo é cínica e cruel diante da morte, mas não contrita. Isso é louvável em termos de 
ficção porque vemos um afastamento do tropo canônico de sair do armário como um drama especial, muito comum em textos sobre sexualidades não hegemônicas. As experiências que esses romances pontuam conseguem fazer isso porque são, por assim dizer, contra a ideia de identidade.

A política identitária é uma estratégia de frisar a diferença para clamar por direitos e visibilidade, mas, como diz Butler (2011, p. 174), corre o risco de mobilizar o "erro necessário da identidade". Por outro lado, para Steven Seidman (2007, p. 134), “as identidades nunca são fixas ou estáveis porque desencadeiam na alteridade, mas porque são oportunidades para uma luta social contínua". As lutas sociais de sujeitos LGBT podem ter sido frutíferas, mas falta ainda um longo caminho para deixarem de ser necessárias. Grande parte dos ganhos se baseou na constituição de identidades positivas, a contrastar com os discursos sobre anormalidade e patologia e com as várias formas de violência. Na introdução comentamos que um dos efeitos dessa política se apresenta numa literatura que pode mais facilmente ser lida como representativa de parte do repertório das vivências LGBT. Contudo, após a leitura dos livros de Lacerda e Heringer precisamos sugerir que eles não se pautam a partir da mesma perspectiva - poderíamos até dizer que os romances se esquivam disso ${ }^{3}$.

As narrativas evitam ao não evocar afetos primária e estereotipicamente essencializados como homo ou bissexuais, por exemplo. O drama de descobrir-se com uma identidade inferiorizada não aparece nessas páginas; elas narram vidas marcadas pela ausência, abandono e solidão. Nem todas as vidas vingam; nem sempre o motivo é a sexualidade. Um lugar-comum da literatura chamada LGBT é apresentar personagens incapacitadas de encontrar a alegria, o amor ou a realização porque são definidas pela identidade em tensão

\footnotetext{
${ }^{3}$ É curioso como os livros são vendidos por suas editoras. Vista do Rio (Cosac \& Naify) traz na capa uma fotografia ampliada e colorida do vírus HIV, apesar do assunto ser muito marginal para a economia do romance. O amor dos bomens avulsos (Companhia das Letras) apresenta na orelha e contracapa sinopses que falam de amor mas ocultam seu teor homossexual. $\mathrm{Na}$ falta de informações sobre essas escolhas editoriais, cabe-nos apontar como elas logram os leitores em potencial dos romances.
} 
com a sociedade fóbica; são narrativas trágicas. Os romances de Lacerda e Heringer também trazem a morte; o fato de ela não chegar no final desloca o sentido de tragédia - são livros, enfim, sobre o desaparecimento do ser amado: Memorabilia em $O$ amor dos homens avulsos; Reminiscência em Vista do Rio.

Coube a Marco-Camilo escrever sobre a metade morta (na verdade, mais viva) como louvor da ruína ou superação da vida. Não é pranto nem os passos da paixão (seus obstáculos, repressão e fim), é a permanência do ser amado em cada segundo desde a sua ausência. Celebração da vida: no final Virgílio sobrevoa a cidade belíssima e maltratada, projetase; Camilo reencontra o amor ao tornar-se pai, dando a si mesmo um sentido.

Homo e bissexualidade passam para o plano de fundo como elementos dos romances, não temas principais. Há uma diferença entre contar histórias que "por acaso são sobre gays" e histórias como essas. Caio Fernando Abreu é o mestre dos contos de amor do primeiro caso: "Terça-feira gorda", "Depois de agosto" etc. - mas também "Aqueles dois". Decorre geralmente dessas narrativas que o amor leva a uma conclusão definida pelo signo da homossexualidade. Logo não é coincidência que amantes ou amigos sejam homens: é só porque são homens que esses contos avançam e se justificam. Trazemos esse exemplo porque o autor é provavelmente o mais estudado na perspectiva da homossexualidade. Mas não devemos ignorar que foram os próprios avanços da política identitária (da qual a leitura dos textos de Abreu também faz parte) que permitiram a criação de histórias nas quais o gênero dos amantes é, de fato, fortuito.

\title{
TWO BOYS: CONSTRUCTION OF LOST LOVE IN TWO CONTEMPORARY NOVELS
}

\begin{abstract}
This article analyzes two contemporary novels: Vista do Rio by Rodrigo Lacerda, and Victor Heringer's $O$ amor dos homens avulsos. The analysis in question seeks to distinguish the composition of two novels that deal with similar subjects: autobiography, memory and affective relationship with another man, sexual or not. Differences in composition lead to different results in terms of both autobiography and memory, but eventually find themselves in terms of sexual identity. Thus both books offer a reading in which the question of identity would be less important in the definition of affective bonds between men.
\end{abstract}


KEYWORDS: Brazilian literature; affectivity; personal narrative.

\section{REFERÊNCIAS}

BARCELLOS, José Carlos. Literatura e homoerotismo em questão. Rio de Janeiro: Dialogarts, 2006.

BARTHES, Roland. A preparação do romance II: a obra como vontade. Tradução de Leyla Perrone-Moisés. São Paulo: Martins Fontes, 2005.

BENJAMIN, Walter. Rua de mão única - Obras escolhidas volume 2. Tradução de Rubens Rodrigues Torres Filho e José Carlos Martins Barbosa. São Paulo: Brasiliense, 1987.

BUTLER, Judith. Relatar a si mesmo: crítica da violência ética. Tradução de Rogerio Bettoni. Belo Horizonte: Autêntica, 2015.

COSTA, Horácio. O Cânone Impermeável: Homoerotismo nas Poesias Brasileira, Portuguesa e Mexicana do Modernismo. In: COSTA, Horácio. et al. (Org.). Retratos do Brasil homossexual: fronteiras, subjetividades e desejos. São Paulo: Editora da Universidade de São Paulo/ Imprensa Oficial, 2010, p. 119-128.

CIORAN, Emil. Breviário da decomposição. Rio de Janeiro: Rocco, 1989.

FLAUBERT, Gustave. Correspondance. Disponível em: < http:/ / flaubert.univ-rouen.fr/correspondance/conard/lettres/lettres1.html>. Acesso em 10 ago. de 2017.

HERINGER, Victor. O amor dos homens avulsos. São Paulo: Companhia das Letras, 2016.

L'ISLE-ADAM, Villiers de. Axël. Disponível em: < https://fr.wikisource.org/wiki/Page: VilliersdeL'Isle-Adam-Axël,1890.djvu/295>. Acesso em 10 ago. de 2017.

LACERDA, Rodrigo. Vista do Rio. São Paulo: Cosac\&Naify, 2004.

MEIRELES, Cecília. Obra poética ou obras completas. Rio de Janeiro: Nova Aguilar, 1987.

PERRONE-MOISÉS, Leyla. Altas literaturas: escolha e valor na obra crítica de escritores modernos. São Paulo: Companhia das Letras, 1998.

WILLIAMS, Raymond. Writting in society. Londres/Nova York: Verso, 1991. 